\title{
LAS JOYAS
}

EN CARLOS

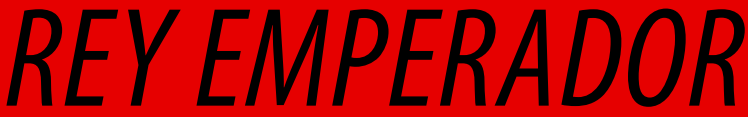

Natalia Horcajo Palomero

Doctora en Historia del Arte e investigadora de joyería

\section{A Nuria Lázaro Milla, mi discípula}

Este artículo no es sino la publicación de la conferencia pronunciada el tres de mayo de 2016, dentro del curso Las Artes Decorativas en tiempos de Carlos V, organizado por la Asociación de Amigos del Museo Nacional de Artes Decorativas en colaboración con la Universidad Complutense de Madrid, y como indica su título, el tema desarrollado en ella giraba en torno a las joyas del siglo XVI, utilizando la serie de TVE, Carlos Rey Emperador ${ }^{1}$, como pretexto.

En 2013 su autora publicó en Estudios de Platería San Eloy, un artículo titulado "Joyas de cine" 2 , tercera entrega de la serie "Otra forma de ver las joyas" iniciada en 2006. En él trabajó sobre la joyería que se utiliza en las películas y las series de televisión, revisando títulos conocidos, dando preferencia a los históricos, porque evidentemente son los más fáciles y a la vez los más difíciles de "vestir con joyas" por las piezas 
y los retratos de los personajes reales que se conservan en museos y la bibliografía existente de joyería, que hay que consultar.

Además, y por desgracia, en las letras de crédito de filmes y series, aparece siempre el figurinista y prácticamente nunca el nombre del encargado de las joyas, salvo excepciones como en el último remake de El gran Gatsby (2013), donde se citaba la firma Tiffany\& $\& \mathrm{CO}^{3}$ que fue la autora de las joyas, muy interesantes y adecuadas para la época que el filme recreaba, los "felices años 20 ".

Así en este trabajo se pudo deducir que en la mayoría de los filmes históricos los diseñadores de vestuario elegían las joyas sin ningún criterio, aunque había una pequeña minoría que sí sabía qué joyas elegir y cómo y dónde había que usarlas.

Entre los ejemplos de "buenos usos" está el airón ${ }^{4}$ que el figurinista Georges K. Benda eligió para que lo llevase prendido del tocado y del pelo Michelle Morgan ${ }^{5}$ como María Antonieta (1956), copia exacta del que la auténtica soberana luce en el retrato de Gautier- Dagoty de 1775, en el Museo del Palacio de Versalles ${ }^{6}$.

¿Y que es un airón? Pues es un broche para el pelo o el tocado, formado por una base de oro esmaltado o no, engastado con piedras preciosas y perlas, o no, que se remata en el ápice por un penacho de plumas de ave o un símil hecho en el mismo oro y con las mismas piedras engastadas. De origen español surge en el siglo XVI, siendo su momento mayor de esplendor en la segunda mitad7.

O en un ejemplo más reciente, Sandy Powell acertó al poner sobre la cabeza de Emily Blunt en La reina Victoria (2009), la tiara fringe que la soberana lucía en un dibujo de Edward Thomas Parris de 18379. Tiara mandada hacer por Jorge III para su esposa la reina Adelaida y que después se adaptó para Victoria y que llevaría la actual soberana, Isabel II, el día de su boda, conservándose en el Tesoro Real Inglés ${ }^{10}$.

El "mal ejemplo" se encuentra en dos filmes también con reina, Elizabeth (1998 y 2007), en ellos, Cate Blanchett, vestida por Alexandra Byrne, lleva dos airones rematados por penachos de plumas tan altas que más bien parecen adornos propios de una vedette ${ }^{11}$, cuando en el Retrato de La Armada Invencible, en la Galería Nacional de Retratos de Londres, datado en 1588 y atribuido hasta hace muy poco a Georges Gower, la reina lleva un magnífico airón del Renacimiento ${ }^{12}$.

Pero... ¿̇y en la serie española Carlos Rey Emperador qué ocurre con las joyas? De vestuario ${ }^{13}$ se ha encargado Pepe Reyes, que ha sido bastante fiel a la manera de vestirse en el siglo XVI, copiándola de forma fidedigna de los retratos de los personajes auténticos o de otros coetáneos, pero le han fallado algunas joyas, quizás porque su reproducción exacta suponía tiempo para documentarse y un gasto excesivo y se carecía de presupuesto para esa partida. La Joyería Méndez Vieira de La Alberca (Salamanca) ha sido la que ha cedido las joyas a Pepe Reyes, pero quizás Luis Valencia y López- Linares han podido proporcionar también algún ejemplar. Lo de menos es cuál ha sido o si han sido las tres, lo importante es que cuando se reproduce una joya del siglo que sea, hay que hacerlo bien y en algunos casos ha habido extravíos, por eso, el estudio comparativo de algunas joyas de los personajes reales o de la época y los de ficción ha resultado ser muy interesante.

\section{LAS JOYAS DEL EMPERADOR CARLOS V}

Aunque hay retratos del auténtico Carlos de niño, como en la serie aparece por primera vez al llegar a España con 17 años, parece más conveniente, puesto que se trata de hacer un estudio paralelo entre realidad histórica y ficción cinematográfica, empezar por aquellas imágenes en las que Carlos tiene aproximadamente esa edad (Fig. 1).

El joven Carlos de la serie lleva pocas joyas, como ocurría en la realidad. El rey emperador era a este respecto muy sobrio, el Toisón era fijo, quizás porque era una joya de Estado, pero había otros tipos que le gustaban, como las insignias o enseñas prendidas en la gorra y las sortijas.

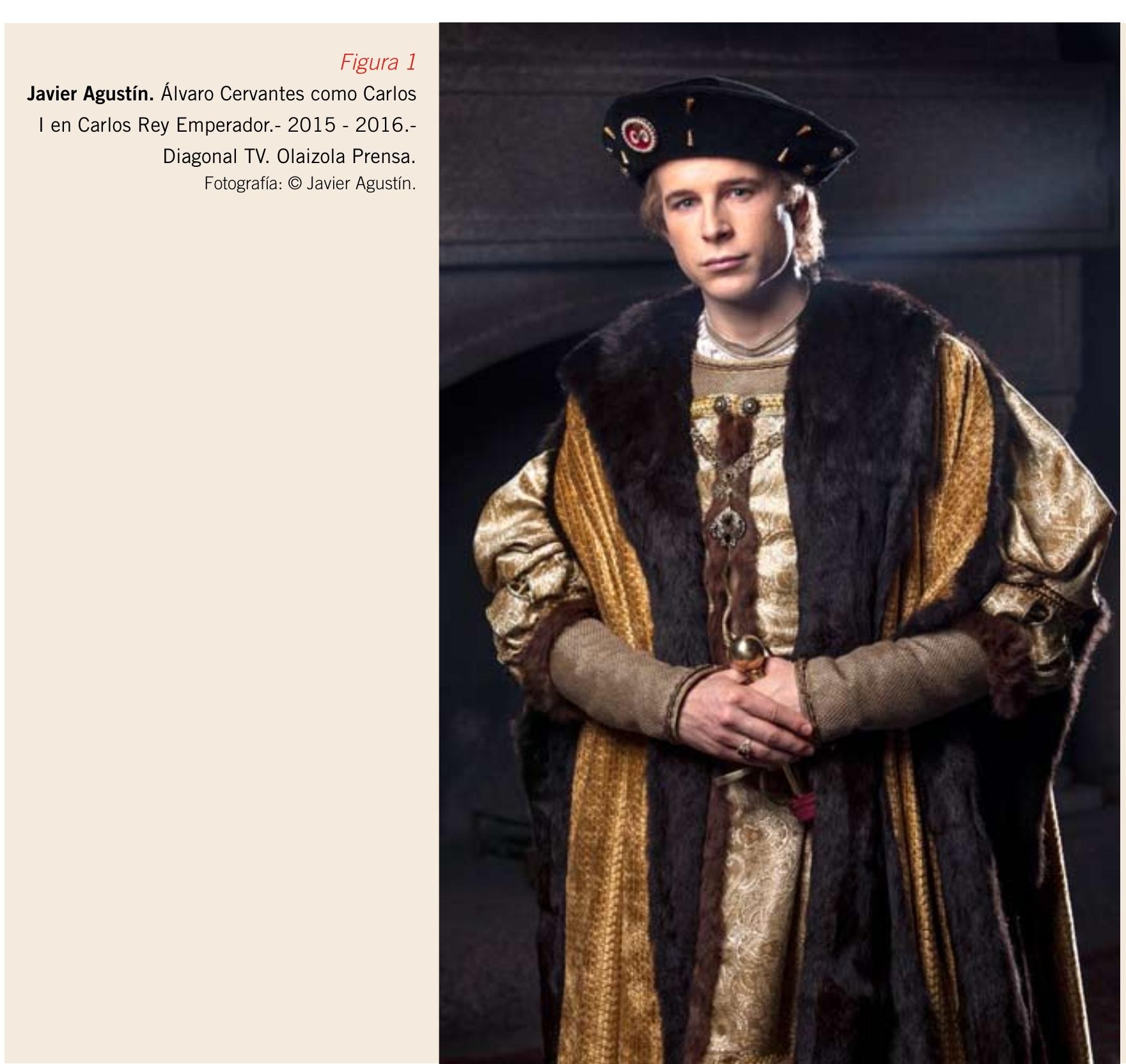


La Orden del Toisón había sido fundada por el duque Felipe el Bueno de Borgoña en 1430 , bajo el patrocinio de San Andrés ${ }^{14}$. Carlos lo recibió prácticamente con un año de edad, y tenía el número 111 dentro de la Orden, más adelante sería nombrado Maestre de la misma.

Si se compara un Collar auténtico como el ejemplar borgoñón del siglo XV en el Museo Kunsthistorisches de Viena ${ }^{15}$, con el que lleva el Carlos de la serie, se observa que si bien el cordero se ajusta al modelo, la cadena es de eslabones mucho más finos.

Un dato importante a tener en cuenta, como se verá más adelante, es que cuando el cordero va suspendido del collar, se llamará Gran Toisón, cuando lo hace de cadenas o de un cordón, entonces es el Pequeño Toisón.

\section{Carlos creía en las propiedades de las piedras} preciosas, prefería las engarzadas con turquesas, porque la turquesa protegía de las caídas del caballo, manteniendo ileso al caído, mientras ella se rompía.

En cuanto a las insignias redondas prendidas en la gorra, el Carlos de la serie lleva una rodeada de perlas, con dos " $\mathrm{C}$ " enfrentadas bajo una corona real y no es posible ver nada más, pero como es una copia acertada de la que lleva en los retratos de Bernard Van Orley en el Museo del Louvre, de circa $1516^{16}$ y en el Museo de Bellas Artes de Budapest, de circa 1519/2017, se sabe que era la Cruz de San Andrés con un eslabón tipo "B" del Toisón y el Cordero pinjante, ambos elementos de su escudo. Las insignias por efecto de la perspectiva se ven ovales.

En otros dos retratos, uno de Bernhard Strigel en la Galería Borghese de Roma de circa 1518 y el otro de Escuela Flamenca en el Museo Fitzwilliam de Cambridge datado circa 1515, aunque parece posterior, el por entonces monarca lleva otras insignias.

La del retrato de Strige 18 , redonda, es parte de la divisa de la Orden del Cisne, fundada en 1443 por el elector Federico II de Brandenburgo y destinada a defender causas sociales. En el centro tiene a la Virgen con el Niño sobre un cuarto de luna, y la inscripción “O + MATER + DEI+ MEMENTO + MEI” (Oh Madre de Dios recuérdame).

La del retrato de Escuela Flamenca19, que se ve oval, como ya se ha indicado más arriba, por efecto de la perspectiva, tiene al parecer una escena de lucha entre centauros, aunque no se aprecia bien. Lleva además otra insignia redonda más, prendida al pecho, de la que es imposible también distinguir la temática que parece ser floral. $Y$ tres sortijas que parecen un añadido posterior porque no están pintadas de forma similar a las otras joyas. En los cuatro retratos citados lleva el Gran Toisón.

Estas insignias no se conservan, pero de las que sí se sabe el paradero, se ha creído oportuno citar dos ejemplares. Una de ellas lleva su propio retrato ${ }^{20}$, es de oro esmalInsignia de la Conversión de San Pablo. Alemania, Circa 1550 OTrustees of the British Museum

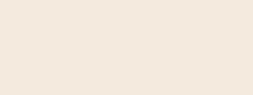

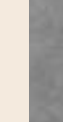

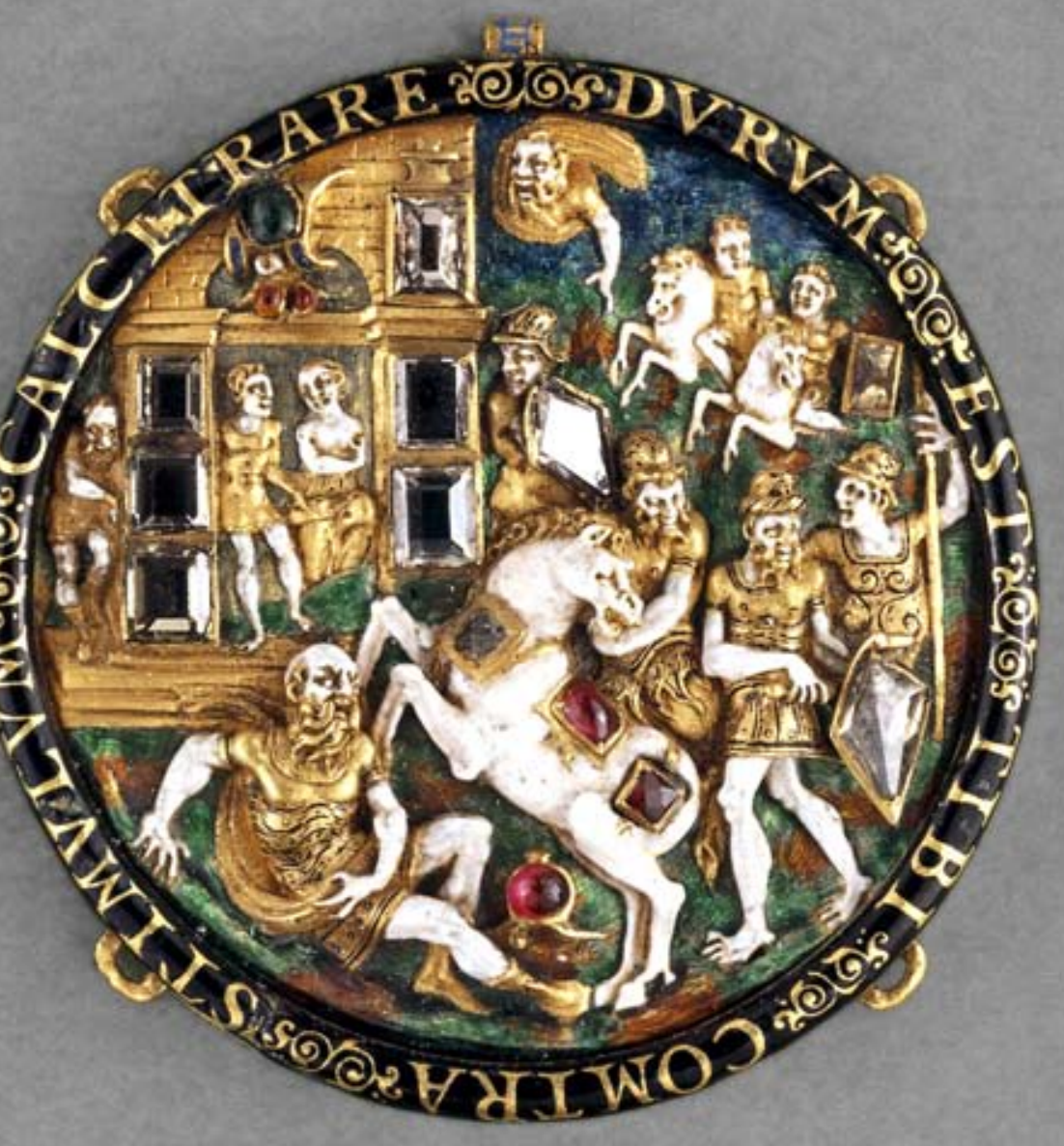

tado en ronde rosse, está datada en 1520 y posiblemente se hizo en Malinas (Flandes) o España, se conserva en el Museo Kunsthistorisches de Viena.

Y parece muy interesante, para que ver la evolución de estilo, esta otra que pudo pertenecer a su hijo Don Juan de Austria, Jeromín. Es un trabajo posiblemente alemán de circa 1550, en el Museo Británico de Londres²1 (Fig. 2).

El tema que desarrolla, es La conversión de San Pablo, con una inscripción en el anverso, "DVRVM + EST + TIBI + COMTRA + STIMVLVM + CALCITRARE" (Es duro para ti cocear contra el aguijón) y otra en el reverso en italiano que dice:

"Joya que estuvo en la gorra del Generalísimo D. Juan de Autria y que el mismo colocó con su mano en la de Camillo Capizucchi como aparece registrado en el Libro de la Casa de Capizucchi, Tomo I, a C."

Aunque este Libro se perdió, posiblemente pudo suceder lo descrito en este documento, pues don Juan y Camillo Capizucchi lucharon juntos en Lepanto (1571).

A Carlos le gustaban las sortijas y en la serie lleva muchas, pero fieles al siglo XVI, prácticamente ninguna, salvo una engarzada con una piedra oscura oval cabujón, que recuerda un ejemplar italiano con un ópalo de mediados del XVI, en el Museo Poldi Pezzoli de Milán²2. 
Y con el pelo largo y barba corta es coronado Emperador del Sacro Imperio Romano-Germánico en Aquisgrán en 1520 (Fig. 6). Pero en realidad, Carlos fue coronado dos veces, la primera efectivamente allí, en Aquisgrán, la segunda en Bolonia, diez años después, en 1530. En la coronación de la serie posiblemente para el Carlos en tronizado se siguió la estética, salvando las distancias, del Napoleón en el trono de Ingres $(1806)^{28}$ en el Museo de La Armada de París, recientemente expuesto en el Museo del Prado.

\section{... en la primera coronación, recibió la espada de} Carlomagno, la corona y el anillo imperiales, el cetro y el orbe, en la segunda, el sable, la corona, el cetro y el orbe.

No se han localizado imágenes pictóricas de las coronaciones de Carlos, pero Manuel Fernández Álvarez en Carlos $V$, el Cesar y el hombre, señala que en la primera, recibió la espada de Carlomagno, la corona y el anillo imperiales, el cetro y el orbe, y en la segunda, el sable, la corona, el cetro y el orbe ${ }^{29}$.

En la serie se muestra con la corona ${ }^{30}$ y el orbe ${ }^{31}$ que se conservan en el Museo Kunsthistorisches de Viena. Es imposible que la primera sea de Carlomagno ya que fue coronado emperador en el año 800, siglo IX, y esta corona es de fines del siglo X y la Cruz un añadido de comienzos del XI. Carlos si la pudo usar, aunque lo más seguro es que utilizase la de su abuelo Maximiliano I que aparece registrada entre los bienes que quedaron en Yuste al tiempo de su fallecimiento en $1558^{32}$.

$Y$ un problema similar sucede con el orbe de circa 1200 y el sable ${ }^{33}$ de mediados de siglo $\mathrm{X}$, ambos posteriores al emperador galo, pero anteriores a Carlos por lo que ta vez los usó.

En la serie, no ha salido la Coronación Imperial de Bolonia, la más importante, pues fue coronado por consejo de su Canciller Mercurino Gattinara, por el Papa Clemente VII.

Hay un dibujo en el Museo Británico, de circa 1547, de Sebastiano del Piombo ${ }^{34}$ del Papa y el Monarca sentados dialogando con las coronas de fondo, pero ambas quedan bastantes desdibujadas, especialmente la de Carlos, que como parece Imperial, tal vez fue la que empleó en Aquisgrán, o la citada de su abuelo, desde luego de la que no puede tratarse es de la que mandó hacer el Emperador Rodolfo a Jan Vermeyen en $1602^{35}$

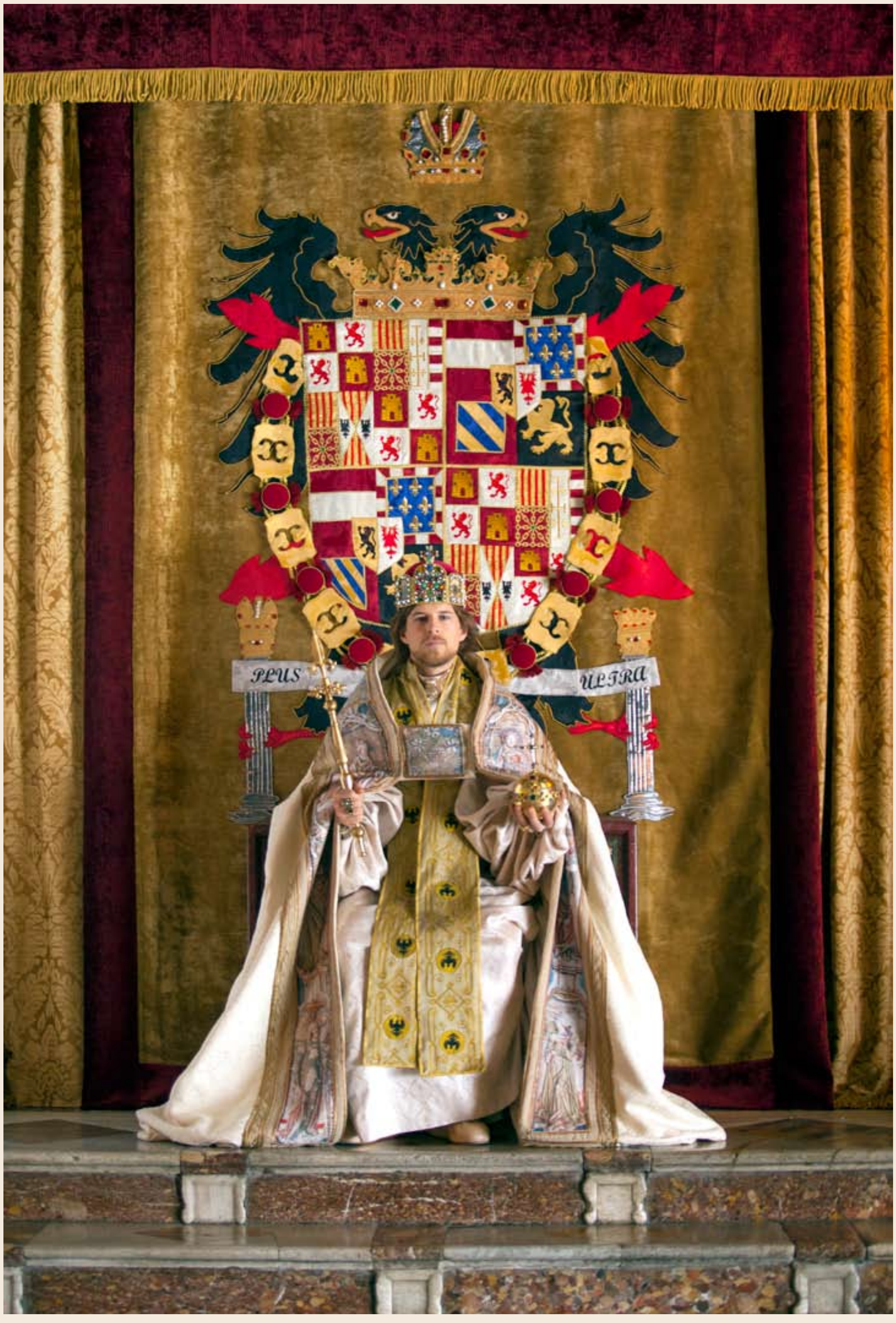




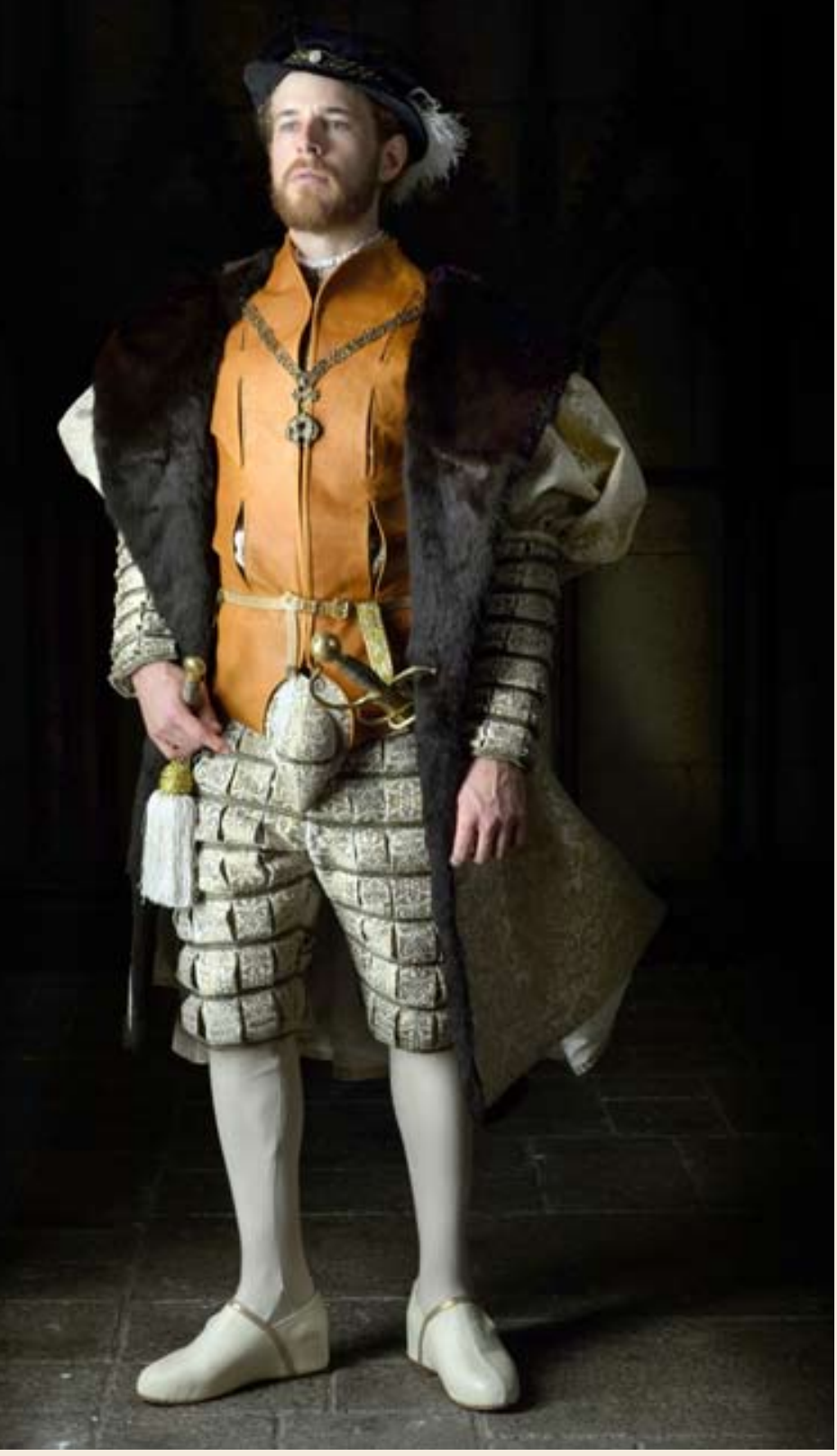

Figura 7

Manuel Fiesta. Álvaro Cervantes como Carlos I y V en Carlos Rey Emperador. 2015- 2016.- Diagonal TV. Fotografía: Olaizola Prensa. @ Manuel Fiesta

El corte de pelo del Carlos de la serie, indica que ya ha pasado a una nueva etapa (Fig. 7), la de los retratos de Seisenegger de 1532 en el Kunsthistoriches ${ }^{36}$, y Tiziano de 1533 en el Museo del Prado (Fig. 8), prácticamente iguales en cuanto a la imagen, pero diferentes en calidad, superior en el maestro veneciano.

La moda ha cambiado y Carlos se ha sumado más o menos al nuevo estilo. El Gran Toisón ha sido sustituido en los retratos, que no en la serie, por un par de cadenas con el Pequeño Toisón pinjante, y aparecen dos nuevas joyas, una cintura de oro, con el tipo de eslabones que serían copiados a posteridad (segunda mitad siglo XX) por Cartier en los Maillon Panthère, y un amoscador.

De origen español y del $\mathrm{XVI}$, el amoscador es un mango de oro esmaltado o no y
Figura 8

El Emperador Carlos $\mathrm{V}$ con un perro. Tiziano, Vecellio di Gregorio. 1533. Museo del Prado, Madrid. O Museo Nacional del Prado

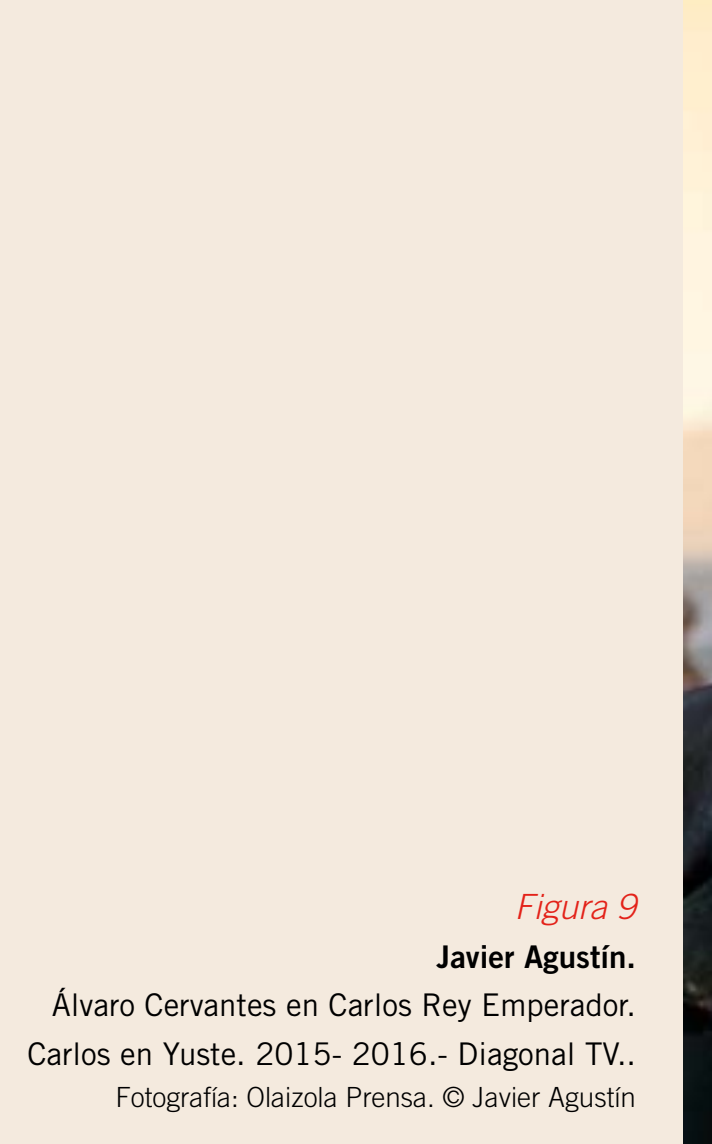

engastado con perlas y piedras preciosas, al se ajustan plumas o hilos de seda con el objetivo de ahuyentar insectos ${ }^{37}$.

Merece la pena contemplar el amoscador de Tiziano en el retrato del Prado, es en sí mismo una auténtica obra de Arte.

Carlos debía atraer estos insectos si se tiene en cuenta la investigación de los doctores D. Julián de Zulueta y D. Pedro L. Alonso, que defienden que fue un mosquito quien le transmitió el paludismo que le ocasionó la muerte y no la gota como se venía creyendo tradicionalmente.

Tras la muerte de Isabel, el rey-emperador adoptó el color negro en su ropa, como posteriormente haría su hijo tras la muerte de su tercera esposa Isabel de Valois, y entonces se puede apreciar que lleva el Pequeño Toisón colgado de un cordón, no solo en sus retratos, como el de Tiziano de circa $1548^{38}$ en la Alte Pinakothek de Munich, también en las imágenes de la serie (Fig. 9), que en esta ocasión le siguen fielmente.

Y así siguió hasta su muerte en Yuste en 1558, desposeído de sus cargos de Rey que había dejado a su hijo Felipe II y Emperador a su hermano, Fernando I. 


\section{LAS JOYAS DE LA EMPERATRIZ ISABEL}

Isabel Avis o Isabel de Portugal, fue su esposa. Los matrimonios reales que se celebraron en España durante el siglo XVI tuvieron un ceremonial bastante complicado, primero, la boda por poderes en la nación de origen de la futura reina, después, un rito de bendiciones y una misa de velaciones ya en su nuevo reino, en este caso, en la ciudad de Sevilla, en los Reales Alcázares, en marzo de 152639.

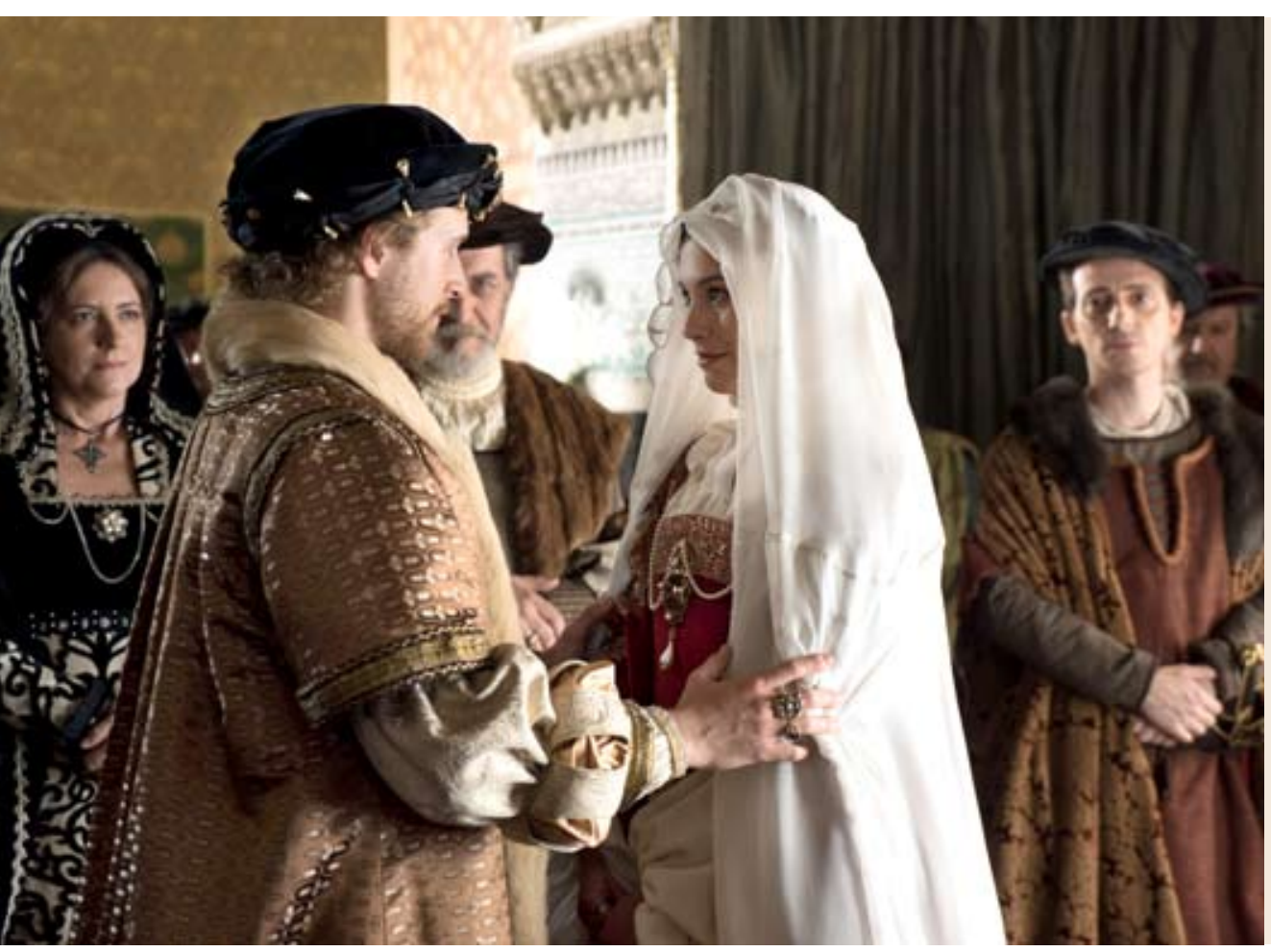

Figura 10

avier Agustín. Álvaro Cervantes y Blanca Suárez en Carlos Rey Emperador. Misa de velaciones. 2015 - 2016.- Diagonal TV.
En esta ceremonia (Fig. 10) hubo un intercambio de regalos: Carlos le entregó una sortija con un diamante, piedra de la que se pensaba que representaba la castidad protegía la fidelidad conyugal. Isabel, por su parte, le dio otra engastada con un rubí, del que se decía que protegía de las heridas de lanza, espada o bala y que quizás eligió pensando en el carácter militar de su esposo.

A Isabel, como ya avanzó Mazarío Coleto ${ }^{40}$, no le gustaban las joyas demasiado, prefería los ropajes y telas ricas. En el retrato de la Emperatriz por Tiziano en el Museo del Prado (Fig. 11) que fue pintado, en 1548 , es decir post mortem, pues la reina había muerto en 1539 , no lleva el joyel que le había enviado Carlos a Portugal y que había sido de su abuelo Maximiliano, de oro esmaltado, formado por troncos y lazos y engastado con una gran piedra, en este caso el diamante corazón, con una perla pera pinjante. Joyel del que se desconoce el paradero. El del retrato es de oro, cruciforme, trabajado con flores de lis y engastado con cuatro perlas redondas en los ángulos y en el centro, superpuestos, un diamante y un rubí, algo mayor, cuadrados, en talla tabla y monturas cuadrifolios o lunetas, con una perla pera pinjante de Terarique, que había comprado la Emperatriz a $\mathrm{D}^{a}$ Isabel de Bobadilla, viuda de gobernador Pedrarías. Lo lleva prendido en el vestido, no del hilo de perlas, que igualmente

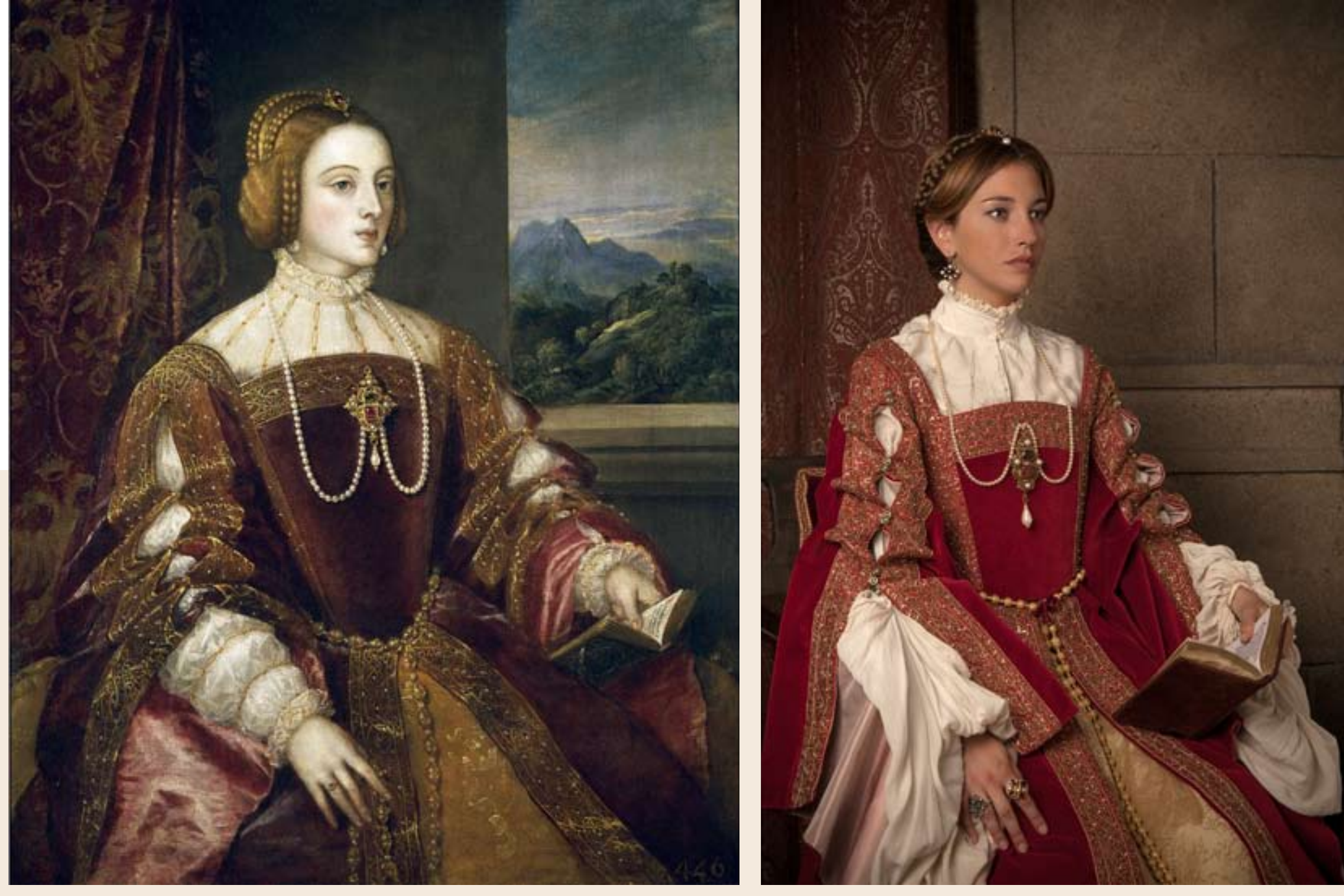

Figura 11

La Emperatriz Isabel de Portugal.

Tiziano, Vecellio di Gregorio. 1548. Museo del Prado, Madrid. ○ Museo Nacional del Prado

Figura 12

Javier Agustín. Blanca Suárez como Isabel de Portugal en Carlos Rey Emperador. 2015- 2016.- Diagonal TV Fotografía: Olaizola Prensa.@ Javier Agustín

va suspendido a la ropa por detrás del joyel. Otro pequeño joyel lobulado con una piedra cuadrada tabla engastada y una perlitas redondas en los ejes y colgando, lo lleva sujeto al cabello. En las orejas, unas perlas pera y en la cintura un cinturón de eslabones ovales, las piezas, de oro, alternando las entre piezas de perlas redondas, También lleva, en el dedo anular de la mano derecha, la sortija que tal vez le regaló Carlos en la misa de velaciones.

Había otro retrato, esta vez doble, de Carlos e Isabel, obra de Tiziano, que se quemó en el incendio del Alcázar en 1734 pero del que se conserva una copia por Rubens anterior a 1625, en el Palacio de Liria de los duques de Alba en Madrid ${ }^{41}$. El traje y el joyel, son diferentes a los del retrato del Prado, posiblemente para parecerse al atuendo del camafeo en sardónice de León Leoni en el Museo Metropolitano de Nueva York, que lo data en 1550, y que sin duda Tiziano debió de ver ${ }^{43}$. Este joyel ha inspirado otro de la serie, circular, engastado de piedras y con tres perlas lágrimas pinjando, la central algo mayor.

En la serie, se ha intentado reproducir (Fig. 12) el retrato individual de Tiziano en el Museo del Prado, pero hay cambios, en el vestido y las joyas. Los pendientes son diferentes, tal vez porque la actriz no va peinada exactamente como la auténtica Emperatriz; también es distinta la cintura y en su mano derecha aparecen dos sortijas. El joyel del 


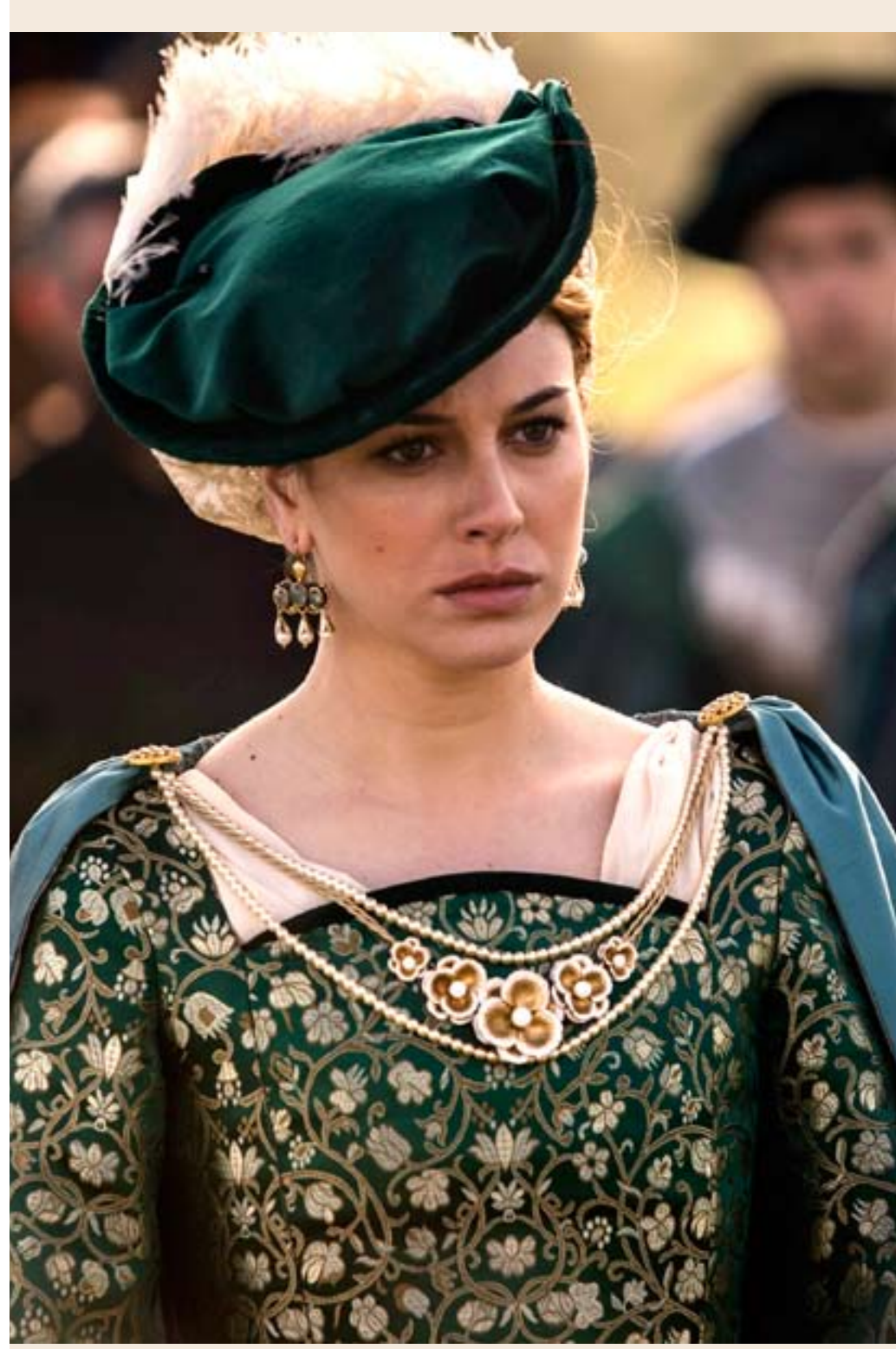

Figura 13

Javier Agustín. Blanca Suárez como Isabel de Portugalen Carlos Rey Emperador. 2015.- Diagonal TV. Fotografía: Olaizola Prensa.๑ Javier Agust

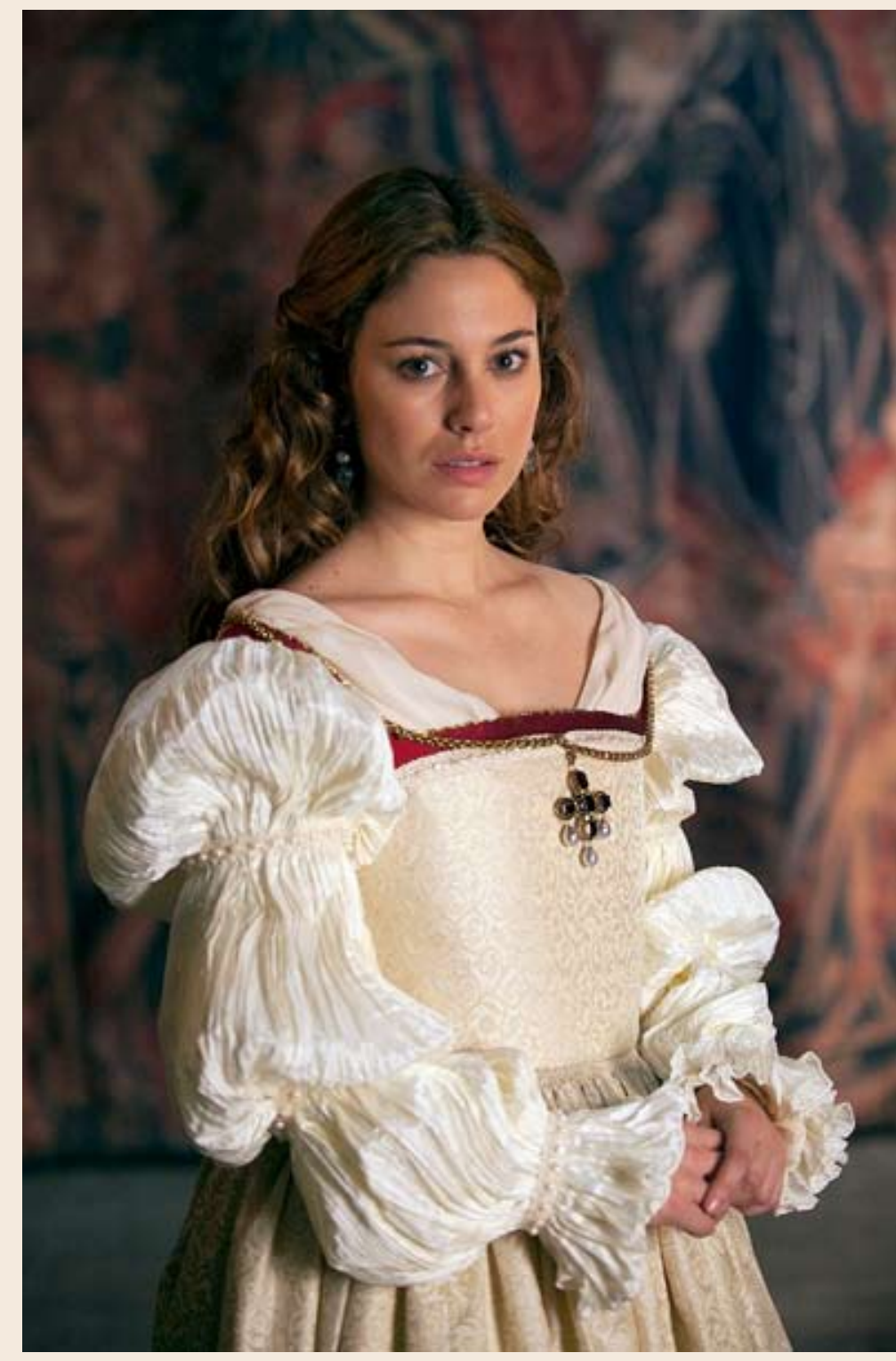

Figura 14

Javier Agustín. Blanca Suarez como Isabel de Portugal en Carlos Rey Emperador. 2015- 2016. Diagonal TV. Fotografía: Olaizola Prensa.@ Javier Agustín

Es interesante también citar una gargantilla que han copiado con licencias de un
¿retrato de Isabel? por Jan Cornelisz Vermeyer, similar a otra pintura de Joos Van Cleve de $1528^{49}$, ambas al parecer en el Museo de Arte Antiga de Lisboa, que se desconoce si pueden ser retratos muy fiables, pero desde luego el collar, formado por $\mathrm{C}$ de dos en dos adosadas, alternando el esmalte blanco y negro, con un florón central del que pinja una perla pera, se ha copiado de estos retratos.

Otro tipo joyas del XVI unido a la devoción y muy utilizado en España, que se ha elegido para la Isabel de la serie, han sido las cruces (Fig. 14). Una de ellas, junto con el vestido, se ha copiado de un posible retrato de ella o de otra Isabel, la hermana de Carlos, que fue reina de Dinamarca, representada como la Magdalena por un autor anónimo del siglo XVI, en el Museo Real de Bellas Artes de Bélgica ${ }^{50}$.

Es una cruz griega, posiblemente engastada con cristales de roca, con los brazos rematados en forma de flor de lis y tres perlas lágrimas pinjando, similar a un ejemplo en el Louvre, de oro esmaltado con diamantes, un topacio y perlas, posible trabajo español del XVI51 y que fue legada por Davillier, el autor de Recherches sur l'orfévrerie en Espagne, au Moyen Âge et a la Renaissance.

En España 52 las cruces favoritas eran las realizadas en oro esmaltado y piedras preciosas, como la anteriormente citada; los crucifijos, como el ejemplar en el Instituto de Arte de Chicago ${ }^{53}$, y las que tenían representados los Símbolos de la Pasión en el anverso y cavidades conteniendo reliquias en el reverso, como la del Museo Arqueológico de Madrid ${ }^{54}$. Ambas de finales del siglo XVI.

La verdad es que para Isabel se han hecho muchas joyas, incluyendo sortijas que por el tamaño de las imágenes fijas no son fáciles de trabajar como pasaba con las de Carlos, las sortijas eran unisex, y las que medio se aprecian, no siguen patrones del siglo $\mathrm{XVI}$, como éstos ejemplos que se citarán a continuación y que sí lo son.

Se trata de cinco sortijas y un diseño para su realización. Este último localizado en el Museo Británico, es un dibujo anónimo de tres sortijas de circa 1560-7055.

En cuanto a las sortijas, la primera, en el Museo de Artes Decorativas de París, de oro engastado con esmeraldas, la central cabujón, las laterales tablas, es un trabajo francés 
de fines del siglo XVI56. La segunda, en el mismo museo, de oro esmaltado y engastado con una esmeralda tabla, es trabajo italiano de mediados del siglo ${ }^{57}$. La tercera y la cuarta, en el Museo Victoria y Alberto de Londres son, una sortija de circa 1585, de oro esmaltado de blanco y negro, con un zafiro rosa tabla ${ }^{58}$, y la otra del sur de Alemania y de circa 1580, lleva un camafeo con la cabeza de Medusa, engastado en el chatón ${ }^{59}$

\section{LAS JOYAS DE OTROS MIEMBROS DE LA FAMILIA IMPERIAL}

Pero Carlos e Isabel no son los únicos Habsburgo importantes en la serie. Su núcleo familiar fue decisivo en muchos de los acontecimientos que se vivieron y así aparecen reflejados con gran acierto.

De Juana, la madre, no hay imágenes con joyas en la serie, así que se dejará apartada, para centrarse en las tías de Carlos, Margarita y Catalina. Ambas con poder, más Margarita, gobernadora de los Países Bajos, que Catalina, que fue separada de la Corte a la llegada de la nueva esposa de Enrique VIII, Ana Bolena.

Margarita, que fue una buena gobernadora, tuvo un papel decisivo en la educación de Carlos, incluyendo la política, con preceptores como Guillermo de Croy, Señor de Chievres o Adriano de Utrecht, futuro Papa Adriano VI. No debía de gustarle exhibirse con joyas, tal vez por su temprana viudez. El collar-gargantilla de plata, con un colgante pinjando engastado con una ¿amatista? cabujón que lleva en algunas imágenes es una recreación fantasiosa y en el retrato de la auténtica Archiduquesa, de la primera mitad del siglo XVI por Van Orley en el Museo Real de Bellas Artes de Bélgica, no hay joyas ${ }^{60}$.

Sin embargo, a Catalina (reina de Inglaterra desde 1509 hasta 1533), sí le gustaban las joyas. Con motivo de su coronación, había llevado una corona de oro, con el borde engastado con seis zafiros y perlas; y cuando junto a su esposo Enrique VIII, se encontró con Francisco I de Francia en el Campo de la Tela de Oro, se sabe que llevaba ricas joyas y perlas ${ }^{61}$.

En el retrato de Sittow de comienzos del siglo XVI en el Museo Kunsthistorisches ${ }^{62}$, que no aclara si la retratada es Rosa, la hermana de Enrique, Catalina su esposa o María su hija, las joyas que lleva son una gargantilla de oro esmaltada muy compacta, a manera de cinta, con dos tipos de eslabones, unos decorados con letras K (Katherine) y una perla y los otros con una flor con un diamante engastado en el cáliz; además tiene una cadena larga de oro hecha a base de varias anillas entrelazadas formando cada eslabón. Ambas recuerdan los dibujos de comienzos del siglo XVI del primer Libro de los Llibres de Passanties, catalanes, especialmente la gargantilla, aunque el uso de la letra K podría llevar a pensar en un taller inglés. Evidentemente la K sólo podía llevarla ella.

Los Llibres de Passantíes que en número de siete se conservan en el Archivo Histórico de la ciudad de Barcelona, recogen los exámenes de maestría de los plateros-joyeros catalanes desde 1580 hasta 188363

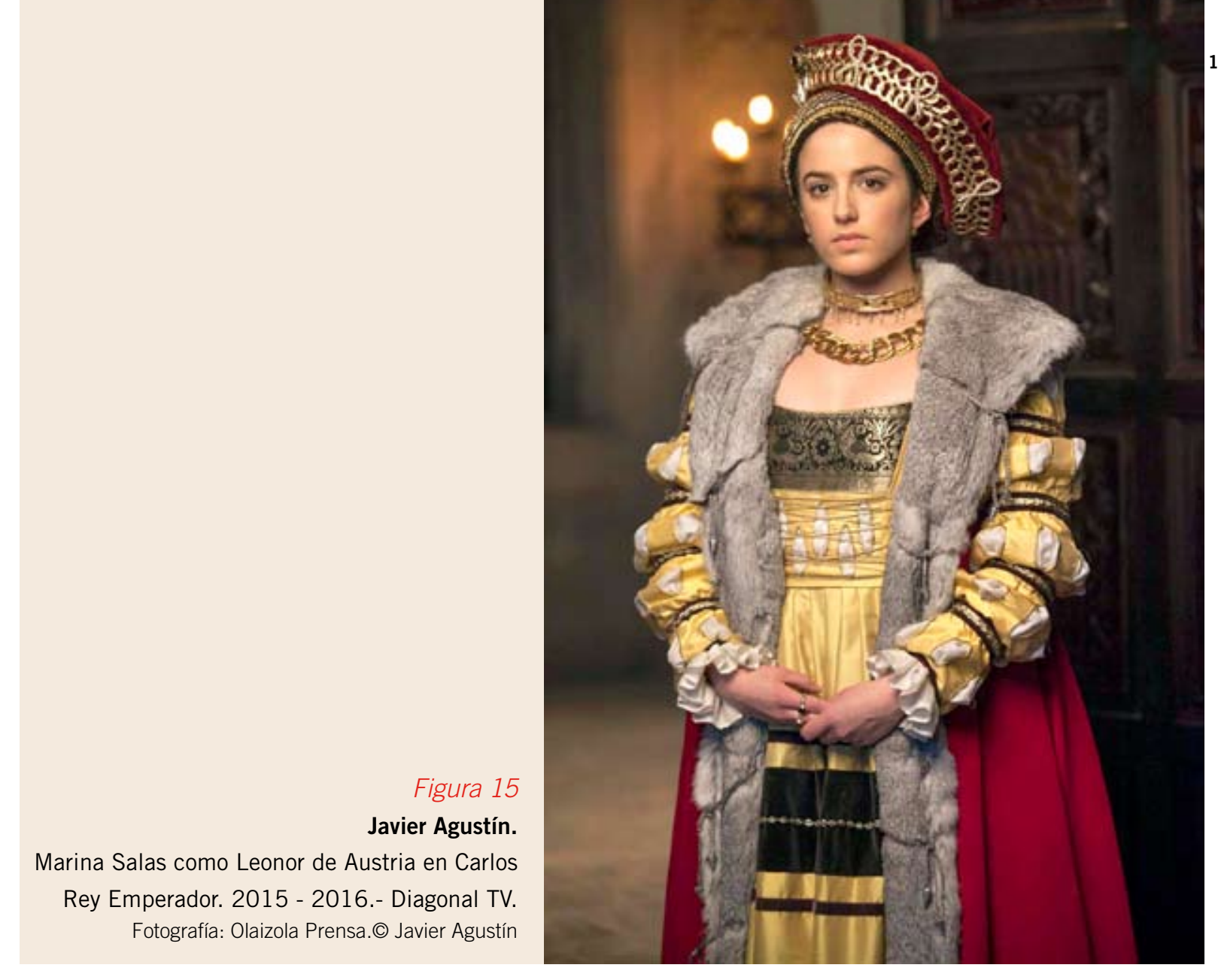

Un símil de este collar lo lleva la Catalina de la serie, también lleva "K", pero es diferente, es menos compacto, parece hecho de hilos de bolitas de cristal doradas.

De los hermanos de Carlos, de Fernando no se comentará nada, porque la única joya que lleva en la serie es el Collar de la Orden del Toisón que ya se ha explicado.

Sin embargo Leonor ha sido la mejor tratada en la serie, se le han hecho varios trajes, acompañados de sombreros. El problema es que ninguno se ajusta al del único retrato que se conserva sin problemas de identificación, el anteriormente citado de Van Cleve. En él, además de dos rubíes tablas rectangulares de buen tamaño cosidos en las mangas, lleva una tira de cabeza con eslabones, las piezas de diamantes y rubíes cuadrados tablas alternado con las entre piezas que llevan perlas, y sobre su oreja izquierda un colgante formado por un eslabón con un diamante cuadrado tabla rodeado de un cordón retorcido de oro, y una gran perla pera pinjante. En el escote, un collar de eslabones alargados de oro esmaltado, iguales, engastados con diamantes cuadrados tablas alternando con perlas, sólo la pieza centra es mayor y en ella el diamante es punta naife, con una cintura con eslabones de perlas y la broncha con otro gran rubí cuadrado tabla. Usa también seis sortijas, tres en cada mano, en la derecha dos engastadas con un diamante, punta naife la del dedo pulgar, y la tercera con un rubí tabla. En la izquierda, dos con rubíes, también en punta naife la del pulgar, y una con un diamante. De las que no se comenta la talla de las piedras es porque no se aprecian bien en la imagen. Lo cierto es que debía tener muchos bienes porque cuando murió dejó a su hija María una cuantiosa fortuna y joyas, tanto portuguesas como francesas.

Para vestir a la Leonor de la serie (Fig. 15), Pepe Reyes ha optado por copiar los modelos de los retratos de Lucas Cranach El Viejo, mucho más vistosos que el sobrio 
de su propio retrato, pero alemanes. Elige, del retrato de una joven de circa 1530, en los Uffizíi ${ }^{64}$ una cadena de eslabones barbados y una gargantilla a manera de tira de oro labrada, engastada con piedras y con pequeñas perlitas redondas pinjantes. Y de retrato de Ana Jagellón, de 1519, por Hans Maler, en el Museo Thyssen Bornemisza de Madrid65, los adornos de perlas en forma de E minúscula del sombrero.

De Isabel, que fue Reina de Dinamarca, se ha citado anteriormente un posible retrato con los atributos de la Magdalena que ha servido de inspiración para vestir y enjoyar a Isabel de Portugal con una cruz. Como el personaje apenas tiene presencia en la serie, no se estudiará aquí.

María solo estuvo casada cuatro años (1522- 1526) con Luis II Jagellón, Rey de Hungría, pues pronto quedó viuda, siendo reclamada por Carlos que la nombró Gobernadora de los Países Bajos a la muerte de su tía Margarita, cargo que ejerció desde 1531 a 1551. A María también le debían de gustar las joyas.

En la imagen de la serie lleva entre otras joyas, además de unos pendientes inventados, un joyel cuadrangular, engastado con una piedra que simula un diamante, con cuatro perlas redondas en las esquinas y una perla pera pinjante, que intenta parecerse, sin mucho éxito, a los auténticos, que eran mayoritariamente cruciformes.

Se conservan dos colgantes alemanes de fines del siglo XVI que son un ejemplo de cómo tendrían que haber sido estos colgantes renacentistas o joyeles. En oro esmaltado, engastados con piedras preciosas y perlas. Ambos fueron propiedad de Lady Rothschild66.

En el retrato de María de 1519 por Hans Maler, en la Kunstsammlungen der Veste Coburg, luce una gargantilla de la que pende un colgante con la Cruz de Jerusalén.

Un colgante parecido aparece recogido en el folio 30 del "Kleinodienbuch" anteriormente citado y en el Museo Arqueológico Nacional de Madrid se conserva también un colgante similar, con las mismas piedras redondas oscuras facetadas, pero de fines del siglo XV|69.

En el retrato de 1524 por Hans Krell70 en la Staatsgalerie in der Residenz Bamberg, Bayer Staatsgemäldesammlungen, la Reina tiene prendido en la gorra un joyel o colgante renacentista con monograma, en concreto las letras IHS, engastado con diamantes y tres perlas pequeñas redondas pinjantes. Estas letras son las tres primeras del nombre de Cristo en griego. También podrían ser interpretadas como la divisa de la Compañía de Jesús, lesus habemus socium, (Tenemos a Jesús de amigo), pero fue fundada por Ignacio de Loyola en 1534, fecha posterior a la del retrato.

Un joyel, muy similar, aunque sin perlas pinjando, se conserva en la Biblioteca Nacional Francesa en París. Esta datado a fines del siglo XVI. En el anverso tiene diamantes, y en el reverso, esmaltados, los símbolos de la Pasión ${ }^{71}$. Posiblemente se trata de un trabajo español por comparación del esmalte con el de la cruz del Arqueológico citada anteriormente.
Catalina, la hermana pequeña que había nacido en España como su hermano Fernando, apenas sale en la serie, pero se sabe que le gustaban mucho las joyas.

Las imágenes trabajadas no permiten apreciar las joyas que lleva, destaca una en la que lleva un rollo a la morisca ${ }^{72}$ decorado con perlas, unos pendientes cuadrados engastado con una piedra y un collar de perlas de río, que en aquella época no se usaban, con un medallón del que apenas se ve nada. Ninguna de estas joyas es del siglo XVI.

... si se quieren hacer series históricas se debe ser riguroso no sólo con los datos que se manejan, sino también al vestir y adornar con joyas a los personajes que una vez fueron y ya no están.

En otra de las imágenes se ve que lleva un collar con perlas peras pinjantes, pero no se aprecia con detalle y el detalle es muy importante a la hora de estudiar joyería porque las joyas son pequeñas, aunque de todas formas no es una joya renacentista.

Para estudiar las joyas de la Catalina real (1507-1578), se ha recurrido a un retrato pintado por Antonio Moro circa 1552- 1556 en el Museo del Prado ${ }^{73}$. Las joyas vistas en él son muy bonitas y buenas, y hay muchas. En el cabello, una tira de cabeza de oro con piezas y entre piezas, engastadas alternativamente con diamantes talla punta y perlas redondas. En las orejas luce unos pendientes formados por una especie de florón con dos volutas o motivo de orejas adosadas, y tres perlas redondas pinjantes, los que hemos visto anteriormente similares en Leonor. Alrededor del cuello una gargantilla muy compacta, que vuelve a recordar los primeros exámenes de los Llibres, elaborada con dos tipos de eslabones, las piezas tienen una flor de cinco pétalos engastada alternativamente con diamantes y rubíes, las entre piezas, dos perlas. En la cintura lleva un escudo coronado, con un gran rubí cabujón engastado en una montura lobulada con alas y un diamante tabla en una montura similar, con tres perlas redondas atravesadas por permios. En la parte inferior dos especies de balaustres cada uno con otra perla. Ha sido imposible desvelar todo lo referente a este escudo, no parece que sea el de Portugal, al menos no coincide ni con el contemporáneo a la reina ni con el actual, $n$ es el escudo de la Casa Avis. En cuanto a las sortijas, lleva muchas, en los dedos pulgar, índice, anular y meñique de ambas manos. Llamando la atención que las de la izquierda tengan engastados diamantes cuadrados y rectangulares tablas, y las de la derecha rubíes redondos y ovales cabujones.

Se podrían seguir comparando muchas más imágenes de la serie con ejemplares de siglo XVI, pero sirva la selección hasta aquí expuesta y estudiada, para demostrar, que si se quieren hacer series históricas se debe ser riguroso no sólo con los datos que se manejan, sino también al vestir y adornar con joyas a los personajes que una vez fueron y ya no están. 


\section{APÉNDICE}

"Mas se les haze cargo de otra corona ynperial de oro, que fue del emperador maxi(miliano) que tienen el primer cerco de abaxo VII çafires y IIII balaxes y III placas vazias donde solia auer piedras entre las quales çafiras y balaxes ay qatorce troços de perlas de cinco los XIII y otros de a IIII que le faltaba vna la de en medio. En el segundo ay VII çafires grandes y III balaxes y IIII plaças vazias sin piedras $y$ XIII troços de perlas de a VII perlas cada vno y vno a VI que son XIIII, que le falta una, y ençima de los dichos dos çercos esta la corona que tiene, VII florones gran des y VII pequeños entre los grandes, y en todos los grandes y pequeños florones ay XLI çafiras y en cada floron de los grandes ay vna plaça vazia en que parece que ha estado pieça, y ay mas, XLI balaxes y un floron dellos en lo alto esta una plaça vazia que paresçe que avia estado un balax, y en el medio de los dichos florones ay dos plaças vazias y al pie dellos ay otras çinco plaças vazias y en la trasera de la dicha corona esta una piedra grisola verde, y en los dichos florones grandes y pequeños hay CCCL perlas dellas pinjantes, y en la delantera de la dicha corona ay vna cruz que tiene seis troços de ados perlas cada vno, y dos plaças vacias en que estaban perlas, y $\mathrm{V}$ plaças vazias en que estavan piedras y en la trasera de la dicha cruz ay tres balaxes y una çafira en el medio, y seis troços de perlas de a II y II plaças vazias una para perlas y otra para piedras, y al rrededor de la cruz por los lados ay $V$ troços de a dos perlas y XIX agujeros donde paresçe que ha avido piedras y perlas y sobre el cerco del teatro de oro ay VIII çafiras y VI balaxes y una grisoleta y IX plaças vazias donde avian estado piedras, en las quales entra la plaça que esta en la cresta del teatro y junto a esta plaça ay vn agujerito ay mas XXII troços de perlas de a VII entre las quales faltan V perlas de las de en medio y el dicho çerco por debaxo tiene vna chapa de oro lisa que peso toda la dicha corona asi como esta dicho con sus piedras y perlas, XX marcos y dos ochavas, lo qual se peso sin el bonetillo que tiene la dicha corona que es de tela de oro rassa forrado en damasco blanco dos vezes, que con el dicho bonetillo peso la dicha corona XX marcos, tres o(nças) I o(chava. La qual rrescivieron los susodichos según par(esçio) por en dicho entrego"74.

\section{NOTAS}

${ }^{1}$ Antes de nada quiero expresar todo mi agradecimiento a Diagonal TV, a su servicio de Prensa, Olaizola Comunicación, y a Dạ Nayla Vega, por su amabilísima atención, y el envío, con permiso de reproducción, de numerosas imágenes de la serie. Extiendo el agradecimiento a Charo Lapausa y al Museo del Prado, al Museo Británico y al Museo Getty, por cederme gratuitamente las imágenes que les he solicitado.

2 HORCAJO PALOMERO, N., "Joyas de cine. Otra forma de ver las joyas. 3" en RIVAS CARMONA J. (coord.), Estudios de Platería. San Eloy 2013, Murcia, Universidad de Murcia, 2013, pp. 235- 248

${ }^{3} \mathrm{https}$ ://www.tiffany.com.mx/WorldOfTiffany/TiffanyStory/Design/JazzAgeGlamour.aspx (septiembre 2016)

${ }^{4}$ En Francia el término airón se convierte en aigrette y este tipo de joya no fue utilizado hasta el siglo XVII. En el texto está denominado airón para poderlo relacionar con los otros ejemplos.

${ }^{5} \mathrm{http} / / / \mathrm{www}$.gettyimages.fr/detail/photo-d'actualit\%C3\%A9/it-was-a-pretty-head-marieantoinette-lost-if-she-photo-dactualit\%C3\%A9/515488074 (septiembre 2016)

${ }^{6} \mathrm{http}: / /$ www.culture.gouv.fr/public/mistral/joconde_fr?ACTION=CHERCHER\&FIELD_1=RE F\&ALUE_1=000PE009098 (septiembre 2016)

7 HORCAJO PALOMERO, N., Joyería Europea del siglo XVI. Estudio tipológico y temático. Madrid, Editorial de la Universidad Complutense, 1992, Vol. II, T IV, pp. 115-116.

8 https://www.filmin.es/pelicula/la-reina-victoria (septiembre 2016)

https:/www.royalcollection.org.uk/collection/search\#/1/collection/917912/queenvictoria-at-drury-lane-theatre-15-november-1837 (septiembre 2016)

${ }^{10}$ MUNN, G., Tiaras, London, V\&A Publishing, 2002, p. 32, fotos 19 y 20. https:// royalexhibitions.files.wordpress.com/2010/05/760041.jpg (septiembre 2016) 
${ }^{11}$ https://es.pinterest.com/pin/37225134398952003/ y https://es.pinterest.com/ pin/496592296382553226/ (septiembre 2016)

$12 \mathrm{http}$ ://www.npg.org.uk/collections/search/portraitLarge/mw02077/Queen-Elizabeth-I?L inkID=mp01452\&search=sas\&sText=elizabeth $+\mid \&$ role $=s i t \& r N o=8 \quad$ (septiembre 2016)

${ }^{13}$ Dado que mi trabajo es sobre joyería, no voy a entrar en cuestiones de indumentaria. Las personas que estén interesadas en este tema deben consultar los trabajos de Carmen Bernis.

${ }^{14} \mathrm{El}$ collar se compone de dos tipos de eslabones: unos están formados por dobles espadas de fuego entrelazadas a manera de "B" en alusión al ducado de Borgoña, y los otros por brillantes piedras pedernales, rodeadas de llamas. Lleva colgando un cordero suspendido por el lomo, con doble sentido, religioso y mitológico. Religioso por recordar, del Libro de los Jueces del Antiguo Testamento de la Biblia, a Gedeón y la ayuda que Yahvé le prestó en su lucha contra los madianitas al concederle las pruebas que el juez pedía, cuando la piel del cordero extendida delante de su tienda amaneció mojada de rocío y el campo que la rodeaba seco, y a la madrugada siguiente, seca, y el campo mojado. Y mitológico, porque alude a la expedición de Jasón y los Argonautas, con ayuda de Medea, en busca del vellocino de oro, recogida en la Medea de Eurípides y las Metamorfosis de Ovidio. El collar tiene la inscripción: "Golpea, antes que la llama centellee", y el cordero: "Estoy al frente con el valor del esfuerzo". HORCAJO PALOMERO, N., ob. cit., Vol. II, T. IV, p. 128.

$15 \mathrm{http}: / /$ bilddatenbank.khm.at/viewArtefactlmageLarge?image=http://bilddatenbank. khm.at/images/500/SK WS XIV_263 ret.jpg\&backuid=http://bilddatenbank.khm.at/ viewArtefact?id=100661 (septiembre 2016)

${ }^{16} \mathrm{http}$ ://art.rmngp.fr/en/library/artworks/barend-van-orley_portrait-de-charles-quint-a-Iage-de-16-ans-environ (septiembre 2016)

${ }^{17} \mathrm{http} / / /$ www.szepmuveszeti.hu/adatlap_eng/portrait_of_charles_v_barend_10822 (septiembre 2016)

${ }^{18} \mathrm{http}: / /$ www.bildindex.de/?+pkunstler:strigel\%20+pkunstler:bernhard\#|home (septiembre 2016)

19 https://es.pinterest.com/pin/301037556317615703/ (septiembre 2016)

${ }^{20}$ MULLER, P. E., Jewels in Spain 1500-1800, Nueva York, The Spanish Society of America, 1972, p. 45, foto 45 derecha; e Idem, Joyas en España 1500-1800, Madrid, Ediciones El Viso, 2012, p. 52, fig. 61; y HORCAJO PALOMERO, N., "La imagen de Carlos V y Felipe II en las joyas del siglo XVI", Archivo Español de Arte, núm 297, 2002, pp. 23- 38

${ }^{21}$ HORCAJO PALOMERO, N. ob. cit., 1992, Vol. I, T. II, p. 803; HACKENBROCH, Y., Enseignes, Renaissance hat jewels, Florencia, S.P.E.S. 1996, pp. 175-178; THORNTON, D., A Rothschild Renaissance. Treasures from the Waddesdon Bequest, Londres, The British Museum Press, 2015, pp. 204- 207; https://www.google.com/culturalinstitute/beta/asset/hat-badge/7QGOjjorYIM2A (septiembre 2016); y http://www.britishmuseum.org/research/collection_online/ collection_object_details.aspx?objectld=38978\&partld=1 (septiembre 2016)

$22 \mathrm{http} / / /$ www.museopoldipezzoli.it/\#!/en/discover/collections/1903 (junio 2016)

${ }^{23}$ HORCAJO PALOMERO, N., “Carlos V y los amuletos de turquesas”, Goya, núm. 138 1977 , pp. 350- 356
${ }^{24}$ http://collections.vam.ac.uk/item/O117053/ring-unknown/\# (septiembre 2016)

${ }^{25}$ HORCAJO PALOMERO, N. ob. cit., 1992, Vol. I, T. II, p. 809. http://www.metmuseum.org/ art/collection/search/460424? sortBy=Relevance\&amp;ft=renaissance+jewels+lehman+collec tion\&amp;pg=1\&amp;rpp=20\&amp;pos=19 (septiembre 2016)

${ }^{26}$ HORCAJO PALOMERO, N. ob. cit., 1992, Vol. I, T. II, p. 782. http://www.getty. edu/art/collection/objects/1114/unknown-maker-hat-badge-representing-prudencefrench-1550-1560/ (septiembre 2016)

27 HORCAJO PALOMERO, N., "Etienne Delaune, orfebre", en RIVAS CARMONA, J. (coord.) Estudios de Platería. San Eloy 2005, Murcia, Universidad de Murcia, 2005, pp. 213- 226.

${ }^{28} \mathrm{http}: / /$ www.wga.hu/support/viewer/z.html (junio 2016)

29 FERNÁNDEZ ALVÁREZ, M., Carlos V, el César y el Hombre, Madrid, Espasa Calpe, 1999, pp. 132 y 419.

${ }^{30} \mathrm{http}: / /$ bilddatenbank.khm.at/viewArtefactlmageLarge?image=http://bilddatenbank . khm.at/images/500/SK_WS_XIII_1_104.JPG\&backuid=http://bilddatenbank.khm.at/ viewArtefact?id=100430 (septiembre 2016)

${ }^{31} \mathrm{http}: / /$ bilddatenbank.khm.at/viewArtefactlmageLarge?image=http://bilddatenbank. khm.at/images/500/SK_WS_XIII_2_201502_01.jpg\&backuid=http://bilddatenbank.khm.at/ viewArtefact?id=100444 (septiembre 2016)

32 El documento con la descripción está al final como apéndice.

${ }^{33} \mathrm{http}: / /$ bilddatenbank.khm.at/viewArtefactlmageLarge?image=http://bilddatenbank khm.at/images/500/SK_WS XIII_5_12979.JPG\&backuid=http://bilddatenbank.khm.at/ viewArtefact?id=100469 (septiembre 2016)

${ }^{34} \mathrm{http}: / /$ www.britishmuseum.org/research/collection online/collection object details/ collection_image_gallery.aspx?assetld=24468001\&objectld=713393\&partld=1 (septiembre 2016)

$35 \mathrm{http}: / /$ bilddatenbank.khm.at/viewArtefactlmageLarge?image=http://bilddatenbank khm.at/images/500/SK_WS_XIA_1_12930.JPG\&backuid=http://bilddatenbank.khm.at/ viewArtefact ?id $=100360$ (septiembre 2016)

${ }^{36} \mathrm{http}: / /$ bilddatenbank.khm.at/viewArtefactlmageLarge?image=http://bilddatenbank khm.at/images/500/GG_A114.jpg\&backuid=http://bilddatenbank.khm.at/ viewArtefact?id=1777 (septiembre 2016)

${ }^{37}$ HORCAJO PALOMERO, N., ob. cit., Vol II, tomo IV, pp.118- 119

38 http://www.wga.hu/support/viewer/z.html (junio 2016)

${ }^{39}$ HORCAJO PALOMERO, N., "Reinas y joyas en la España del siglo XVI" en AA.VV., El Arte en las Cortes de Carlos V y Felipe II, Madrid, CSIC, 1999, pp. 141-150.

${ }^{40}$ MAZARÍO COLETO, M. del C., Isabel de Portugal: Emperatriz y Reina de España, Madrid, Escuela de Historia Moderna, Consejo Superior de Investigaciones Científicas, 1951.

${ }^{41} \mathrm{http} / / /$ www.fundacioncasadealba.com/coleccion/ficha_c.php?bjdi=17 (septiembre 2016) 
${ }^{42} \mathrm{http}: / /$ www.metmuseum.org/art/collection/search/198270?sortBy=Relevance\&amp;ft= leon+leoni+cameos\&amp;pg=1\&amp;rpp=20\&amp;pos=1 (septiembre 2016)

${ }^{43} \mathrm{Se}$ comenta sobre un primer retrato de la Emperatriz por Tiziano, con este mismo traje y joyel, que al parecer ella había enviado a Flandes y que el Emperador reclamó a su muerte y se llevó a Yuste. Perdido el original, según la Fundación Casa de Alba, el marqués de Santo Domingo conserva una copia. Lo he visto (http://retratosdelahistoria.blogspot.com. es/2012 04_01_archive.html) y francamente no me parece una pintura italiana y mucho menos de Tiziano, en todo caso sería una tabla flamenca y no me convence.

44 HORCAJO PALOMERO, N. "Los colgantes renacentistas", Espacio, Tiempo y Forma, núm. 11, 1998, pp. 81-102.

${ }^{45} \mathrm{https}$ ://www.youtube.com/watch?v=YO27rXNw_kk (septiembre 2016)

$46 \mathrm{http}$ //daten.digitale-sammlungen.de/ db/bsb00006598/images/index. html?id=00006598\&nativeno=41r (septiembre 2016); $\mathrm{h}$ http://daten.digitale-sammlungen

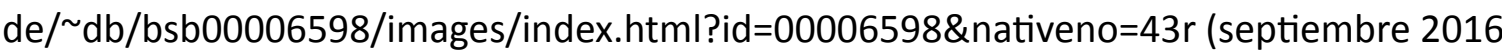

${ }^{47} \mathrm{http}: / /$ bilddatenbank.khm.at/viewArtefact?id=485 (septiembre 2016)

$48 \mathrm{http}$ ///art.thewalters.org/detail/77410/pair-of-earrings-2/ (septiembre 2016)

49 https://es.pinterest.com/pin/535506211920919229/(septiembre 2016); y https://www. google.es/search?hl=es\&site=imghp\&tbm=isch\&source=hp\&biw=1440\&bih=775\&q=isabel+d e+portugal+museu+de+arte+antiga\&oq=isabel+de+portugal+museu+de+arte+antiga\&gs_l=i mg.3..1058.14834.0.15094.42.15.1.26.26.0.74.805.15.15.0...0...1ac.1.64.img..0.26.814...0j0 i19j0i30i19j0i8i30i19j0i30j0i24.wgdeHOMVNIU\#hl=es\&tbm=isch\&q=isabel+avis++jan+corneli sz+vermeyen\&imgrc=Nd51rFS6BNYRHM\%3A (junio de 2016)

${ }^{50} \mathrm{http} / / /$ www.fine-arts-museum.be/fr/la-collection/ecole-des-pays-basmeridionaux-portrait-presume-disabelle-de-portugal-1501-1539-en-mariemadeleine?string=portrait+Marie-Madeleine (septiembre 2016)

${ }^{51} \mathrm{http}: / /$ cartelen.louvre.fr/cartelen/visite?srv=obj_view_obj\&objet=cartel_23625_24652_ ov012019.001.jpg_obj.html\&flag=true (septiembre 2016)

52 MULLER, P. E., ob. cit., 1972, pp. 66- 68; Idem, ob. cit., 2012, pp. 59- 62; HORCAJO PALOMERO, N., "La sociedad española del siglo XVI y las joyas" en AA.VV., Arte, poder y sociedad en la España de los siglos XV al XX, Madrid, CSIC, 2008, pp. 485-494.

$53 \mathrm{http}: / /$ www.artic.edu/aic/collections/artwork/119968?search_no=10\&index $=66$ (septiembre 2016)

${ }^{54} \mathrm{http}: / /$ ceres. $m c u . e s /$ pages/Viewer?accion=4\&AMuseo=MAN\&Museo=MAN\&Nin $\mathrm{v}=1984 / 106 / 2$ y http://ceres.mcu.es/pages/Viewer?accion=4\&Museo=MAN\&AMuseo=MAN $\& N i n v=1984 / 106 / 2 \&$ txt_id_imagen $=2 \& t x t \_r o t a r=0 \& t x t$ contraste $=0$ (junio 2016)

$55 \mathrm{http}$ //www.britishmuseum.org/research/collection online/collection_object_details/ collection_image_gallery.aspx?assetld $=8512001 \&$ objectld $=720355 \&$ partld $=1$ (septiembre 2016)

${ }^{56} \mathrm{http}: / /$ collections.lesartsdecoratifs.fr/bague-57 (septiembre 2016)

$57 \mathrm{http}: / /$ collections.lesartsdecoratifs.fr/bague-37 (septiembre 2016)
${ }^{58} \mathrm{http}: / /$ collections.vam.ac.uk/item/O115440/ring-unknown/ (septiembre 2016)

59 http://collections.vam.ac.uk/item/O33895/ring-unknown/ (septiembre 2016)

$60 \mathrm{http} / / /$ www.wga.hu/support/viewer/z.html (junio de 2016)

${ }^{61}$ HORCAJO PALOMERO, N., "Reinas y joyas en la Europa del siglo XVI" en RIVAS CARMONA J. (coord.) Estudios de Platería. San Eloy 2010, Murcia, Universidad de Murcia, 2010, pp. 319-337; Y FRASER, A. Las seis mujeres de Enrique VIII, Buenos Aires, Ed. B. Argentina SA, 1998, pp. 73, 261 262,313 y 132

$62 \mathrm{http} / / /$ bilddatenbank.khm.at/viewArtefactlmageLarge?image=http:// bilddatenbank.khm.at/images/500/GG_5612.jpg\&backuid=http://bilddatenbank.khm.at/ viewArtefact?id=1788 (septiembre 2016)

63 HORCAJO PALOMERO, N., ob. cit., 1992, Vol. II, T. III, pp. 86-87.

${ }^{64} \mathrm{http}: / /$ www.wga.hu/frames-e.html?/html/c/cranach/lucas_e/index.html (junio 2016)

$65 \mathrm{http}: / /$ www.museothyssen.org/thyssen/zoom_obra/256 (septiembre 2016)

${ }^{66}$ SMITH, C. H., Jewellery. Yorkshire, Ep. Publishing Limited, 1973, plate XXXII; y https:// archive.org/stream/jewellery00smit\#page/n363/mode/2up (septiembre 2016)

$67 \mathrm{http}: / /$ www.kunstsammlungen-coburg.de/datenbank-gemaelde/details.php (junio 2016)

${ }^{68} \mathrm{http}: / /$ daten.digitale-sammlungen.de/ db/bsb00006598/images/index.html?id=000065 98\&groesser=\&fip=qrsqrseneayaeayaewqeayaweaya\&no=5\&seite=67 (septiembre 2016)

$69 \mathrm{http}: / /$ ceres. $\mathrm{mcu}$.es/pages/Viewer?accion=4\&Museo=MAN\&AMuseo=MAN\&Ninv=5238 0\&txt_id_imagen $=2 \&$ txt_rotar $=0 \&$ txt_contraste $=0$ (septiembre 2016)

70 https://es.pinterest.com/pin/47921183505475753/ (septiembre 2016)

${ }^{71} \mathrm{http} / / /$ medaillesetantiques.bnf.fr/ws/catalogue/app/collection/ record/781?vc=ePkH4LF7IZZLbsMwDESvluQCNTkkTV4nu3bTVYEev08FHATIKouBLc7TyB_ J8uv2dLt2EMvbOxPk4_UZPb2Hx_rw05afirTSI6o5DZSoOImoNViDtRB-4zd-4_f2ZOXSHriBG7iBG7j ZdbjppeNAhhjrEAqUqNC5ZAc51A3f9hHf8A3ftk-GzZKT4-Q4nMM5nBd9d_9dh3VYhxVtwQlOcCJ P5Alf-EFWwARMwARMwARMwJCpnbmvK_EyGQOW-1UyTpJRMAVTMAVT9K9aadcX6P759f3z8bdE27P4t7cRs\$ (junio 2016)

${ }^{72}$ Agradezco el conocimiento de este término a la investigadora Da Dolores Vila Tejero quien así lo puso en conocimiento de los asistentes a su conferencia La indumentaria en tiempos del emperador Carlos: entre la tradición y las modas europeas, pronunciada inmediatamente antes que la mí.

$73 \mathrm{https}$ //www.museodelprado.es/coleccion/obra-de-arte/doa-catalina-de-austria-mujerdel-juan-iii-de/1c4821f2-d46b-4222-bc98-cfa57745b203?searchid=a1819bd4-f9ec-36ae00dc-8ee59dbc86ca (junio 2016)

74 MÁRMOL MARÍN, D. M. del M., Joyas en las Colecciones Reales de Isabel La Católica a Felipe II, Madrid, Fundación Universitaria Española, 2001, p. 245. 